\title{
Association of Congestive Heart Failure and Death with Ankylosing Spondylitis : A Nationwide Longitudinal Cohort Study in Korea
}

\author{
Ki Hwan Bae, B.S., ${ }^{1 *}$ Je Beom Hong, M.D., ${ }^{2 *}$ Yoon Jin Choi, M.D., Ph.D., ${ }^{3}$ Jin Hyung Jung, M.S., ${ }^{4}$ In-Bo Han, M.D., Ph.D., \\ Jung Min Choi, M.S., ${ }^{5}$ Seil Sohn, M.D., Ph.D. \\ Department of Neurosurgery, CHA Bundang Medical Center, CHA University, Seongnam, Korea \\ Department of Neurosurgery, ${ }^{2}$ Kangbuk Samsung Hospital, Sungkyunkwan University College of Medicine, Seoul, Korea \\ Department of Internal Medicine, ${ }^{3}$ Guro Hospital, College of Medicine, Korea University, Seoul, Korea \\ Department of Biostatistics, ${ }^{4}$ College of Medicine, The Catholic University of Korea, Seoul, Korea \\ Department of Medical Device Management and Research, ${ }^{5}$ SAIHST, Sungkyunkwan University, Seoul, Korea
}

Objective : We attempted to discover that Ankylosing spondylitis (AS) has a comprehensive relationship with congestive heart failure and death.

Methods : We used a nationwide database managed by the Korean National Health Insurance Service from 2010 to 2014. Twelve thousand nine hundred eighty-eight patients with a diagnosis of AS and 64940 age- and sex- stratified matching subjects without AS were enrolled in the AS and control groups. Incidence probabilities of 6 years congestive heart failure and death in each group were calculated. The Cox proportional hazard regression analysis was used to estimate the hazard ratio. We divided the AS and control groups into subgroups according to sex, age, income, and comorbidities.

Results : During the follow-up period, 102 patients $(0.79 \%)$ in the AS group and 201 patients $(0.32 \%)$ in the control group developed congestive heart failure $(p<0.0001)$. In addition, $211(1.62 \%)$ subjects in the AS group died during the follow-up period compared to $639(0.98 \%)$ subjects in the control group $(p<0.0001)$. The adjusted hazard ratio of congestive heart failure and death in the AS group was 2.28 (95\% confidence interval [Cl], 1.80-2.89) and $1.66(95 \% \mathrm{Cl}, 1.42-1.95)$, respectively. The hazard ratios of congestive heart failure and death were significantly increased in all of the subgroups.

Conclusion : The incidence rates of congestive heart failure and death were increased in AS patients.

Key Words : Heart failure · Cardiovascular diseases · Death · Spondylitis, Ankylosing · Epidemiology.

- Received : May 10, 2018 •Accepted : June 19, 2018

- Address for reprints : Seil Sohn, M.D., Ph.D.

Department of Neurosurgery, CHA Bundang Medical Center, CHA University, 59 Yatap-ro, Bundang-gu, Seongnam 13496, Korea Tel : +82-31-881-7966, Fax : +82-2-780-5269, E-mail : sisohn@cha.ac.kr

*Ki Hwan Bae and Je Beom Hong contributed equally as the first authors.

This is an Open Access article distributed under the terms of the Creative Commons Attribution Non-Commercial License (http://creativecommons.org/licenses/by-nc/4.0) which permits unrestricted non-commercial use, distribution, and reproduction in any medium, provided the original work is properly cited. 


\section{INTRODUCTION}

Congestive heart failure is a life-threatening disease affecting approximately 26 million people worldwide ${ }^{25}$. Ankylosing spondylitis (AS) is a chronic inflammatory rheumatic disorder that affects the axial skeleton ${ }^{13)}$. Several case reports have focused on congestive heart failure in AS patients ${ }^{1,2,27,29)}$. Studies have also been conducted to ascertain the incidence of congestive heart failure in AS patients ${ }^{11,14,15,31)}$. However, large-scale studies are lacking ${ }^{11,14,31)}$. Although one study did involve more than 10000 people $^{15)}$, it was a cross-sectional study. One study included AS patients in only one city ${ }^{31)}$ and another study involved AS patients who were over 40 years old ${ }^{14)}$.

Several studies have reported death in AS patients ${ }^{26,33)}$, and there are controversies whether AS increases the death rate. A report showed that AS does not have an effect on death ${ }^{6}$. However, other studies suggested that AS patients are more likely to die $\mathrm{e}^{3,5,7,12,20)}$. Most studies about death rate in AS patients are limited by the small sample sizes, ${ }^{3,5-7,20)}$. Although one study investigated the relationship between AS and death in more than 10000 AS patients, it was only about vascular mortality ${ }^{12)}$.

The present study is a nationwide longitudinal cohort study to clarify the risk of congestive heart failure and all-cause death in an AS population.

\section{MATERIALS AND METHODS}

\section{Data source}

Data was acquired from the Korean National Health Insurance Service (NHIS) for 2010 to 2014. NHIS has information about people who have received health care. The NHIS database has extensive information and classifies diseases under the International Classification of Disease (ICD-10) ${ }^{28}$. Researchers who are approved by the official review committee can use this NHIS database, and we acquired the rights to use it from the institutional review board of the CHA Bundang Medical Center of CHA University (IRB No. 2017-08-015).

\section{Patient population}

Initially, 15547 AS subjects were extracted from January 1, 2010 to December 31, 2014 among the total population of the Republic of Korea (50455745 people). Afterwards, 1400 sub- jects who had a previous history of ischemic stroke or acute myocardial infarction or congestive heart failure were excluded. Subsequently, 1159 people younger than 20 years old were excluded. Thus, 12988 subjects were established (Fig. 1). In the next step, $1: 5$ age- and sex- stratified matching was performed using a Greedy digit match algorithm. In this process, 12988 AS patients were matched with 64940 controls $^{17)}$. Both groups were followed up to December 31, 2015.

\section{Definitions of cardiovascular events and comor- bidities}

AS was diagnosed according to the Reduction of Medical Expenses for Rare Complaints Code, V14.0, between January 1, 2010 and December 31, 2014. Cardiovascular events were defined as a new occurrence of myocardial infarction or ischemic stroke or congestive heart failure during the follow-up period. An acute myocardial infarction diagnosis was defined by ICD-10 (I21 and I22) and hospitalization $\geq 1$. The ischemic stroke patients had ICD-10 codes of I63, I64 and hospitalization $\geq 1$ with imaging studies (brain computed tomography or magnetic resonance imaging). A congestive heart failure diagnosis was defined by ICD-10 codes (I50) and hospitalization $\geq 1^{1724,28}$. Comorbidities such as diabetes mellitus (E11-E14), hypertension (I10-I13, I15), and dyslipidemia (E78) were de-

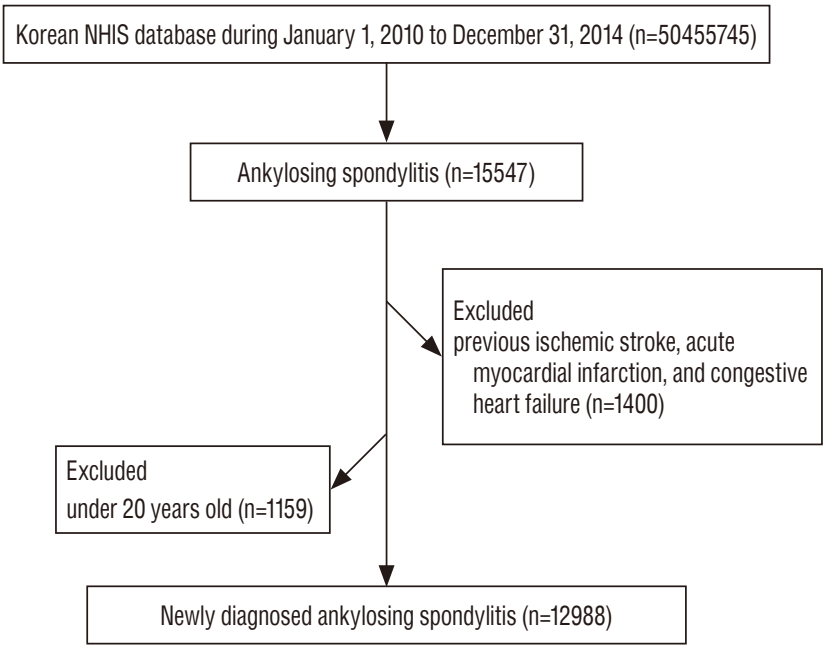

Fig. 1. Procedure for establishment of the study cohort. Among the total population of the Republic of Korea (50455745 people), 15547 Ankylosing spondylitis (AS) subjects were extracted for the period, January 1, 2010 to December 31, 2014. One thousand four hundred subjects who had a previous history of ischemic stroke or acute myocardial infarction or congestive heart failure were excluded. Subsequently, 1159 people younger than 20 years old were also excluded. Eventually, 12988 subjects constituted the base cohort. NHIS : National Health Insurance Service. 
fined by ICD-10 codes with additional information described previously ${ }^{18,19,24)}$.

\section{Statistical analysis}

We used the Chi-square test and Student's t-test to compare the mean differences in the demographic characteristics and comorbidities between the AS and the control groups. Cumulative incidence probabilities of congestive heart failure and death in the AS and control groups were estimated using the Kaplan-Meier method. Differences in survival rates between the two groups were measured using the Wilcoxon's log-rank test. Multivariate analyses of the Cox proportional hazard regression model were conducted to estimate the effects of AS on congestive heart failure and death. The incidence rate was calculated as the number of events per 1000 person-years. Two Cox proportional hazard regression models were applied to estimate the hazard ratio and the corresponding $95 \%$ confi-

Table 1. Characteristics of the AS and control group

\begin{tabular}{lccc}
\hline Variable & AS $(\mathbf{n}=12988)$ & Control $(\mathbf{n = 6 4 9 4 0 )}$ & $\boldsymbol{p}$-value \\
\hline Female & $3566(27.46)$ & $17830(27.46)$ & \\
Age & $40.186 \pm 14.195$ & $40.186 \pm 14.194$ & \\
Age $\geq 40$ & $5,915(45.54)$ & $29575(45.54)$ & \\
Age $\geq 65$ & $864(6.65)$ & $4320(6.65)$ & \\
Diabetes mellitus & $623(4.80)$ & $2447(3.77)$ & $<0.0001$ \\
Hypertension & $1710(13.17)$ & $6199(9.55)$ & $<0.0001$ \\
Dyslipidemia & $1135(8.74)$ & $3763(5.79)$ & $<0.0001$ \\
Congestive heart & $102(0.79)$ & $210(0.32)$ & $<0.0001$ \\
$\quad$ failure & & & \\
Death & $211(1.62)$ & $639(0.98)$ & $<0.0001$ \\
\hline
\end{tabular}

Values are presented as mean \pm standard deviation or number (\%). AS : ankylosing spondylitis dence intervals (CIs). Age and sex were adjusted in model 1. In addition to age and sex, other comorbidities were adjusted in model 2. We organized subgroups in the AS and control group according to sex, age, income, and comorbidities. Age was divided into two groups; those over 65 and under 65 years old. Income was divided into upper/middle and lowest categories. Comorbidities included diabetes mellitus, hypertension, and dyslipidemia. Data measurements were analyzed using SAS version 9.2 software (for Windows; SAS Institute, Cary, NC, USA).

\section{RESULTS}

\section{Characteristics of the AS and control group}

Table 1 showed the baseline characteristics about sex, age, comorbidities, congestive heart failure, and death. There were 12988 subjects in the AS group and 64940 subjects in the control group during the study period. Males (72.54\%) outnumbered females (27.46\%). The mean age of the subjects was $40.19 \pm 14.20$ years. There were significant differences between the two groups in the prevalence rates of diabetes mellitus $(p<0.0001)$, hypertension $(p<0.0001)$, dyslipidemia $(p<0.0001)$, congestive heart failure $(p<0.0001)$, and death $(p<0.0001)$. The incidence rates of congestive heart failure and death were significantly higher in the AS group than those in the control group $(p<0.0001$ and $p<0.0001$, respectively). The other comorbidities of diabetes mellitus, hypertension, and dyslipidemia were significantly higher in the AS group than in the control group $(p<0.0001, p<0.0001, p<0.0001$, respectively, Table 1).

Table 2. Adjusted hazard ratio for cardiovascular events and death in the AS and control group

\begin{tabular}{|c|c|c|c|c|c|c|}
\hline \multirow{2}{*}{ Group } & \multirow{2}{*}{$\mathrm{N}$} & \multirow{2}{*}{ Event } & \multirow{2}{*}{ Duration (hours) } & \multirow{2}{*}{ Incidence rate (\%) } & \multicolumn{2}{|c|}{ Hazard ratio $(95 \% \mathrm{CI})$} \\
\hline & & & & & Model 1 & Model 2 \\
\hline \multicolumn{7}{|c|}{ Congestive heart failure } \\
\hline Control & 64940 & 210 & 227134.68 & 0.92 & 1 & 1 \\
\hline AS & 12988 & 102 & 45307.12 & 2.25 & $2.46(1.94-3.11)$ & $2.28(1.80-2.89)$ \\
\hline \multicolumn{7}{|l|}{ Death } \\
\hline Control & 64940 & 639 & 226338.94 & 2.82 & 1 & 1 \\
\hline AS & 12988 & 211 & 45095.12 & 4.68 & $1.71(1.46-2.00)$ & $1.66(1.42-1.95)$ \\
\hline
\end{tabular}

Model 1 was adjusted for age and sex. Model 2 was adjusted for age, sex, income, diabetes mellitus, hypertension, and dyslipidemia. AS : ankylosing spondylitis, $\mathrm{Cl}$ : confidence interval 


\section{Congestive heart failure in the AS and control group}

Of the 12988 subjects in the AS group, 102 (0.79\%) developed congestive heart failure during the follow-up period

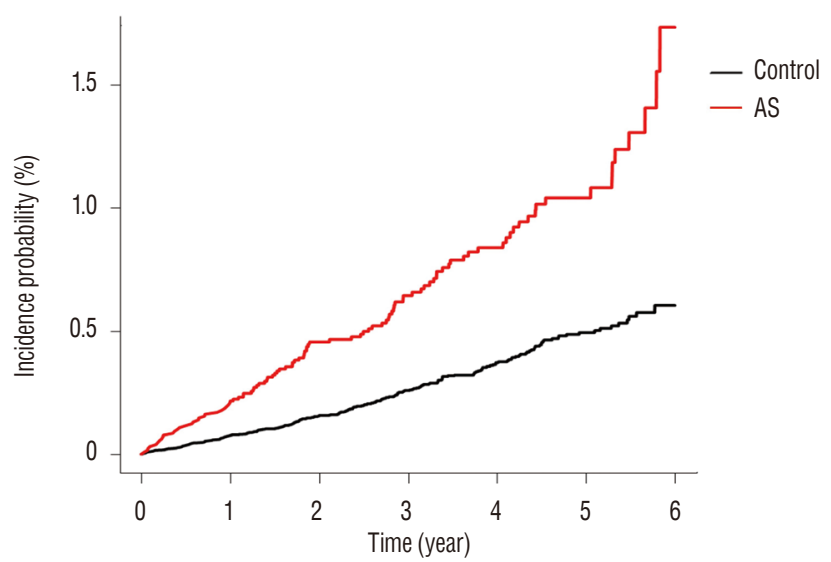

Fig. 2. Comparison of the incidence probability of congestive heart failure between the Ankylosing spondylitis (AS) and control groups during the follow-up period. Kaplan-Meier curves with cumulative hazards of congestive heart failure were used in the AS and control groups. The incidence probability of congestive heart failure in the AS group was significantly higher than that in the control group $(p<0.0001)$. compared to $210(0.32 \%)$ out of the 64940 subjects in the control group $(p<0.0001$, Table 1$)$. In a multivariate analysis of Cox proportional hazards regression model 1 , the hazard ratio of congestive heart failure in the AS group was 2.46 compared to that in the control group (95\% CI, 1.94-3.11; Table 2). In a multivariate analysis of model 2 , the hazard ratio of congestive heart failure in the AS group was 2.28 compared to that in the control group (95\% CI, 1.80-2.89; Table 2, Fig. 2).

In both male and female subgroup, congestive heart failure incidence rate was significantly different between AS and control group (95\% CI, 1.61-2.93; 1.71-3.76; respectively; Table 3). In both age group ( $<65$ and $\geq 65$ ), congestive heart failure incidence rate was significantly different between AS and control group (95\% CI, 1.59-3.09; 1.67-3.30; respectively; Table 3). In both upper/middle and lowest income subgroup, congestive heart failure incidence rate was significantly different between AS and control group (95\% CI, 1.94-3.46; 1.19-2.75; respectively; Table 3). In both non-diabetes and diabetes subgroup, congestive heart failure incidence rate was significantly different between AS and control group (95\% CI, 1.74-2.98; 1.27-3.62; respectively; Table 3). In both non-hypertension and hyperten-

Table 3. Subgroup analysis of congestive heart failure in the AS and control group

\begin{tabular}{|c|c|c|c|c|c|}
\hline \multirow{2}{*}{ Variable } & \multicolumn{2}{|r|}{ AS } & \multicolumn{2}{|r|}{ Control } & \multirow{2}{*}{ Hazard ratio $(95 \% \mathrm{Cl})$} \\
\hline & $\mathrm{N}$ & Incidence rate (\%) & $\mathrm{N}$ & Incidence rate (\%) & \\
\hline \multicolumn{6}{|l|}{ Sex } \\
\hline Male & 63 & 1.91 & 135 & 0.82 & $2.18(1.61-2.93)$ \\
\hline Female & 39 & 3.16 & 75 & 1.21 & $2.55(1.71-3.76)$ \\
\hline \multicolumn{6}{|l|}{ Age } \\
\hline$<65$ & 53 & 1.25 & 107 & 0.50 & $2.23(1.59-3.09)$ \\
\hline$\geq 65$ & 49 & 16.68 & 103 & 6.87 & $2.36(1.67-3.30)$ \\
\hline \multicolumn{6}{|l|}{ Income } \\
\hline Upper/middle & 69 & 2.01 & 143 & 0.81 & $2.60(1.94-3.46)$ \\
\hline Lowest & 33 & 3.00 & 67 & 1.35 & $1.83(1.19-2.75)$ \\
\hline \multicolumn{6}{|l|}{ Diabetes mellitus } \\
\hline No & 80 & 1.86 & 169 & 0.77 & $2.29(1.74-2.98)$ \\
\hline Yes & 22 & 10.07 & 41 & 4.84 & $2.17(1.27-3.62)$ \\
\hline \multicolumn{6}{|l|}{ Hypertension } \\
\hline No & 48 & 1.22 & 125 & 0.61 & $1.96(1.39-2.72)$ \\
\hline Yes & 54 & 9.11 & 85 & 3.93 & $2.64(1.87-3.71)$ \\
\hline \multicolumn{6}{|l|}{ Dyslipidemia } \\
\hline No & 70 & 1.69 & 171 & 0.80 & $2.06(1.54-2.71)$ \\
\hline Yes & 32 & 8.23 & 39 & 3.08 & $3.05(1.89-4.87)$ \\
\hline
\end{tabular}

AS : ankylosing spondylitis, $\mathrm{Cl}$ : confidence interval 
sion subgroup, congestive heart failure incidence rate was significantly different between AS and control group (95\% CI, 1.39-2.72; 1.87-3.71; respectively; Table 3). In both non-dyslip-

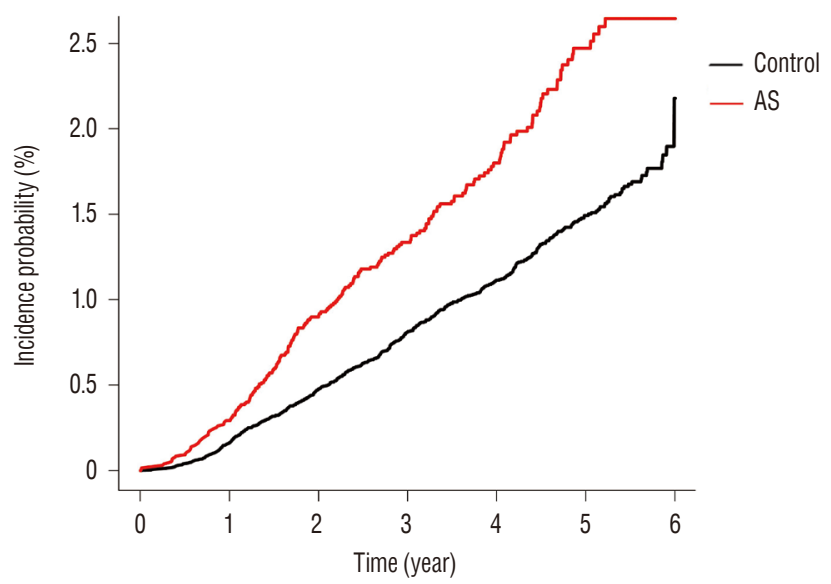

Fig. 3. Comparison of the incidence probability of death between the Ankylosing spondylitis (AS) and control groups during the follow-up period. Kaplan-Meier curves with cumulative hazards of death were used in the AS and control groups. The incidence probability of death in the AS group was significantly higher than that in the control group $(p<0.0001)$. idemia and dyslipidemia subgroup, congestive heart failure incidence rate was significantly different between AS and control group (95\% CI, 1.54-2.71; 1.89-4.87; respectively; Table 3).

\section{Death in the AS and control group}

Of the 12988 subjects in the AS group, 211 (1.62\%) subjects died during the follow-up period compared to $639(0.98 \%)$ subjects in the control group $(p<0.0001$, Table 1$)$. In a multivariate analysis of Cox proportional hazards regression model 1 , the hazard ratio of death in the AS group was 1.71 compared to that in the control group (95\% CI, 1.46-2.00; Table 2). In a multivariate analysis of model 2 , the hazard ratio of death in the AS group was 1.66 compared to that in the control group (95\% CI, 1.42-1.95; Table 2, Fig. 3).

In both male and female subgroup, death rate was significantly different between AS and control group (95\% CI, 1.34-1.92; 1.402.61; respectively; Table 4 ). In both age group ( $<65$ and $\geq 65$ ), death rate was significantly different between AS and control group (95\% CI, 1.09-1.74; 1.62-2.48; respectively; Table 4). In both upper/middle and lowest income subgroup, death rate was significantly different between AS and control group (95\% CI, 1.48-

Table 4. Subgroup analysis of death in the AS and control group

\begin{tabular}{|c|c|c|c|c|c|}
\hline \multirow{2}{*}{ Variable } & \multicolumn{2}{|r|}{ AS } & \multicolumn{2}{|r|}{ Control } & \multirow{2}{*}{ Hazard ratio $(95 \% \mathrm{Cl})$} \\
\hline & $\mathrm{N}$ & Incidence rate (\%) & $\mathrm{N}$ & Incidence rate (\%) & \\
\hline \multicolumn{6}{|l|}{ Sex } \\
\hline Male & 155 & 4.73 & 487 & 2.96 & $1.61(1.34-1.92)$ \\
\hline Female & 56 & 4.55 & 152 & 2.46 & $1.93(1.40-2.61)$ \\
\hline \multicolumn{6}{|l|}{ Age } \\
\hline$<65$ & 90 & 2.13 & 318 & 1.50 & $1.39(1.09-1.74)$ \\
\hline$\geq 65$ & 121 & 42.87 & 321 & 22.00 & $2.01(1.62-2.48)$ \\
\hline \multicolumn{6}{|l|}{ Income } \\
\hline Upper/middle & 134 & 3.92 & 437 & 2.47 & $1.80(1.48-2.18)$ \\
\hline Lowest & 77 & 7.06 & 202 & 4.08 & $1.51(1.15-1.95)$ \\
\hline \multicolumn{6}{|l|}{ Diabetes mellitus } \\
\hline No & 168 & 3.91 & 530 & 2.43 & $1.67(1.40-1.98)$ \\
\hline Yes & 43 & 19.87 & 109 & 13.07 & $1.68(1.17-2.38)$ \\
\hline \multicolumn{6}{|l|}{ Hypertension } \\
\hline No & 138 & 3.52 & 444 & 2.17 & $1.69(1.39-2.04)$ \\
\hline Yes & 73 & 12.33 & 195 & 9.11 & $1.64(1.24-2.14)$ \\
\hline \multicolumn{6}{|l|}{ Dyslipidemia } \\
\hline No & 176 & 4.27 & 576 & 2.70 & $1.62(1.36-1.91)$ \\
\hline Yes & 35 & 9.02 & 63 & 5.00 & $2.07(1.35-3.12)$ \\
\hline
\end{tabular}

AS : ankylosing spondylitis, $\mathrm{Cl}$ : confidence interval 
2.18; 1.15-1.95; respectively; Table 4). In both non-diabetes and diabetes subgroup, death rate was significantly different between AS and control group (95\% CI, 1.40-1.98; 1.17-2.38; respectively; Table 4). In both non-hypertension and hypertension subgroup, death rate was significantly different between AS and control group (95\% CI, 1.39-2.04; 1.24-2.14; respectively; Table 4). In both non-dyslipidemia and dyslipidemia subgroup, death rate was significantly different between AS and control group (95\% CI, 1.36-1.91; 1.35-3.12; respectively; Table 4).

\section{DISCUSSION}

Our study showed that the incidence of AS was 12988 during the study period and that AS increased the risk of congestive heart failure by 2.28 times and the risk of death by 1.66 times. These associations were constant after adjusting for demographics and comorbidities. In addition, the risk of congestive heart failure and death increased in all of the subgroups.

The present study was a nationwide longitudinal study using the NHIS database. NHIS was implemented in $1989^{34)}$, and the NHIS database covers $97 \%$ of people in the Republic of Korea ${ }^{16,28)}$. Nearly all of the incident cases of vascular events would be identified. We analyzed 6 year follow-up data, covering all age groups over 20 . This study also used a clear definition of AS using the Reduction of Medical Expenses for Rare Complaints Code.

The mechanism of which congestive heart failure increased in AS patients is unclear. However, there have been case reports which suggested amyloidosis in patients with both congestive heart failure and $\mathrm{AS}^{8,10)}$. Amyloidosis may cause increase in the myocardial extracellular volume ${ }^{4)}$. Therefore, the increased myocardial extracellular volume can cause heart failure. Inflammation in AS also can cause fibrosis in the aortic root and thickening in the adjacent ventricular septum ${ }^{13)}$. These also may cause congestive heart failure.

The causes of increased death rate in AS are not clear yet as well. AS can produce a restrictive lung function and can cause bilateral apical pulmonary fibrobullous disease ${ }^{13)}$. AS induces inflammatory bowel disease as well ${ }^{13)}$. AS patients have weaker spines. Therefore, they are more vulnerable to trauma and fractures ${ }^{9,23,32)}$. Further studies are warranted to elucidate the causes of increased congestive heart failure incidence rate and increased death rates.
Several limitations in this study should be noted. Due to the basic limit of the NHIS database, this study lacks information related to life habits such as smoking, alcohol consumption, physical activity, and eating patterns. Such factors may affect the cardiac function ${ }^{22,30)}$ and death rate ${ }^{21)}$. Moreover, because vascular risk factors such as diabetes and hypertension and dyslipidemia are insidious disorders, they may not be identified in the NHIS database. Even with this limitation in mind, this is the largest nationwide longitudinal study to show an increased risk of congestive heart failure and death in AS patients.

\section{CONCLUSION}

This nationwide longitudinal cohort study shows an increased risk of congestive heart failure and death in AS patients.

\section{CONFLICTS OF INTEREST}

No potential conflict of interest relevant to this article was reported.

\section{INFORMED CONSENT}

This type of study does not require informed consent.

\section{- Acknowledgements}

This work was supported by Basic Science Research Program through the National Research Foundation of Korea (NRF) funded by the Ministry of Education (NRF-2017R1D1A1B03032980). This work was also supported by a grant of the Korea Health Technology R\&D Project through the Korea Health Industry Development Institute (KHIDI), funded by the Ministry of Health \& Welfare, Republic of Korea (HR16C0002). 


\section{References}

1. Amin $A$, Chitsazan $M, N a v i d ~ H$ : Left ventricular systolic dysfunction in two patients with ankylosing spondylitis: what is the role of corticosteroids? Eur J Rheumatol 3 : 179-181, 2016

2. Aoyagi S, Akashi H, Kawara T, Ishihara K, Tanaka, A, Kanaya S, et al. : Aortic root replacement for Takayasu arteritis associated with ulcerative colitis and ankylosing spondylitis--report of a case. Jpn Circ J 62 : 6468, 1998

3. Bakland G, Gran JT, Nossent JC : Increased mortality in ankylosing spondylitis is related to disease activity. Ann Rheum Dis 70 : 1921-1925, 2011

4. Barison A, Aquaro GD, Pugliese NR, Cappelli F, Chiappino S, Vergaro $G$, et al. : Measurement of myocardial amyloid deposition in systemic amyloidosis: insights from cardiovascular magnetic resonance imaging. J Intern Med 277 : 605-614, 2015

5. Buschiazzo EA, Schneeberger EE, Sommerfleck FA, Ledesma C, Citera $G$ : Mortality in patients with ankylosing spondylitis in Argentina. Clin Rheumatol 35 : 2229-2233, 2016

6. Carter ET, McKenna CH, Brian DD, Kurland LT : Epidemiology of ankylosing spondylitis in Rochester, Minnesota, 1935-1973. Arthritis Rheum 22 : 365-370, 1979

7. Exarchou S, Lie E, Lindström U, Askling J, Forsblad-d'Elia H, Turesson C, et al. : Mortality in ankylosing spondylitis: results from a nationwide population-based study. Ann Rheum Dis 75 : 1466-1472, 2016

8. Fujito $T$, Inoue $T$, Hoshi $K$, Hatano $H$, Kamishirado $H$, Takayanagi $K$, et al. : Systemic amyloidosis following ankylosing spondylitis associated with congestive heart failure. A case report. Jpn Heart J 36 : 681-688, 1995

9. Gazi Boyaci M, Tunay K, Rakip U, Karademir M, Karavelioglu E : Ankylosing spondylitis: a cause of death after minor trauma. Joint Bone Spine $83:$ 456, 2016

10. Ha SJ, Kim WS, Hwang SJ, Woo JS, Shon IS, Bae JH, et al. : A case of systemic amyloidosis following ankylosing spondylitis associated with congestive heart failure. J Am Soc Echocardiogr 22 : 542.e5-e7, 2009

11. Han C, Robinson DW Jr, Hackett MV, Paramore LC, Fraeman KH, Bala MV : Cardiovascular disease and risk factors in patients with rheumatoid arthritis, psoriatic arthritis, and ankylosing spondylitis. J Rheumatol 33 : 2167-2172, 2006

12. Haroon NN, Paterson JM, Li P, Inman RD, Haroon N : Patients with ankylosing spondylitis have increased cardiovascular and cerebrovascular mortality: a population-based study. Ann Intern Med 163 : 409-416, 2015

13. Hochberg MC, Silman AJ, Smolen JS, Weinblatt ME, Weisman MH : Rheumatology, ed 3. St. Louis : Mosby, 2003, p1161

14. Hung YM, Chang WP, Wei JC, Chou P, Wang PY : Midlife ankylosing spondylitis increases the risk of cardiovascular diseases in males 5 years later: a national population-based study. Medicine (Baltimore) 95 : e3596, 2016

15. Kang JH, Chen $\mathrm{YH}$, Lin $\mathrm{HC}$ : Comorbidity profiles among patients with ankylosing spondylitis: a nationwide population-based study. Ann Rheum Dis 69 : 1165-1168, 2010

16. Kang SH, Choi EK, Han KD, Lee SR, Lim WH, Cha MJ, et al. : Underweight is a risk factor for atrial fibrillation: a nationwide populationbased study. Int J Cardiol 215 : 449-456, 2016

17. Lee DH, Choi YJ, Han IB, Hong JB, Do Han K, Choi JM, et al. : Association of ischemic stroke with ankylosing spondylitis: a nationwide longitudinal cohort study. Acta Neurochir (Wien) 160 : 949-955, 2018

18. Lee SR, Choi EK, Han KD, Cha MJ, Oh S: Trends in the incidence and prevalence of atrial fibrillation and estimated thromboembolic risk using the CHA2DS2-VASC score in the entire Korean population. Int J Cardiol $236:$ 226-231, 2017

19. Lee SR, Choi EK, Han KD, Cha MJ, Oh S, Lip GYH : Temporal trends of antithrombotic therapy for stroke prevention in Korean patients with non-valvular atrial fibrillation in the era of non-vitamin $\mathrm{K}$ antagonist oral anticoagulants: a nationwide population-based study. PLoS One 12 : e0189495, 2017

20. Lehtinen $\mathrm{K}$ : Mortality and causes of death in 398 patients admitted to hospital with ankylosing spondylitis. Ann Rheum Dis 52 : 174-176, 1993

21. Li W, Wang DZ, Zhang H, Xu ZL, Xue XD, Jiang GH : Study on smoking attributed death and effects of smoking cessation in residents aged 35 79 years in Tianjin, 2016. Zhonghua Liu Xing Bing Xue Za Zhi 38 : 1533-1536, 2017

22. Nicolozakes AW, Binkley PF, Leier CV : Hemodynamic effects of smoking in congestive heart failure. Am J Med Sci 296 : 377-380, 1988

23. Oh JS, Doh JW, Shim JJ, Lee KS : Leading a patient of ankylosing spondylitis to death by iatrogenic spinal fracture. Korean J Spine $13: 80$ 82, 2016

24. Park CS, Choi EK, Han KD, Lee HJ, Rhee TM, Lee SR, et al. : Association between adult height, myocardial infarction, heart failure, stroke and death: a Korean nationwide population-based study. Int J Epidemiol 47 : 289-298, 2018

25. Ponikowski P, Anker SD, AlHabib KF, Cowie MR, Force TL, Hu S, et al. : Heart failure: preventing disease and death worldwide. ESC Heart Fail $1: 4-25,2014$

26. Prati C, Puyraveau M, Guillot $X$, Verhoeven F, Wendling D : Deaths associated with ankylosing spondylitis in France from 1969 to 2009. J Rheumatol 44 : 594-598, 2017

27. Retief JH, Rossouw DS, Theron MH, Swanepoel HM : Dilated cardiomyopathy in a patient with ankylosing spondylitis. A case report. S Afr Med J 74 : 238-240, 1988

28. Rhee TM, Lee JH, Choi EK, Han KD, Lee H, Park CS, et al. : Increased risk of atrial fibrillation and thromboembolism in patients with severe psoriasis: a nationwide population-based study. Sci Rep 7 : 9973, 2017

29. Sganzerla EP, Riva MA : The disease of the Italian poet Giacomo Leopardi (1798-1837): a case of juvenile ankylosing spondylitis in the 19th century? J Clin Rheumatol 23 : 223-225, 2017

30. Siemienczuk D, Greenberg B, Broudy DR : Effects of eating on cardiac performance in congestive heart failure. Chest 90 : 193-197, 1986

31. Szabo SM, Levy AR, Rao SR, Kirbach SE, Lacaille $D$, Cifaldi M, et al. : 
Increased risk of cardiovascular and cerebrovascular diseases in individuals with ankylosing spondylitis: a population-based study. Arthritis Rheum 63 : 3294-3304, 2011

32. Thomsen $A H$, Jurik $A G$, Uhrenholt $L$, Vesterby $A$ : Traumatic death in ankylosing spondylitis. J Forensic Sci 55 : 1126-1129, 2010

33. Wysham KD, Murray SG, Hills N, Yelin E, Gensler LS : Cervical spinal fracture and other diagnoses associated with mortality in hospitalized ankylosing spondylitis patients. Arthritis Care Res (Hoboken) 69 : 271-277, 2017

34. Yang BM : The role of health insurance in the growth of the private health sector in Korea. Int J Health Plann Manage 11 : 231-252, 1996 